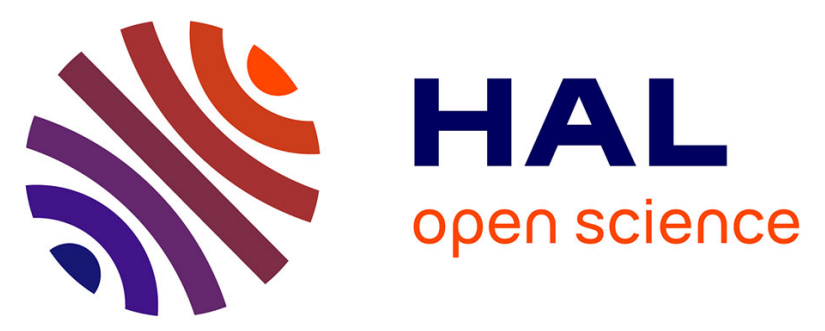

\title{
Safety of Bioelectrical Impedance Analysis in Patients Equipped With Implantable Cardioverter Defibrillators
}

Philippe Meyer, Anne-Marie Makhlouf, Louis P. Mondouagne Engkolo, Florence Trentaz, Ronan Thibault, Claude Pichard, Haran Burri

\section{- To cite this version:}

Philippe Meyer, Anne-Marie Makhlouf, Louis P. Mondouagne Engkolo, Florence Trentaz, Ronan Thibault, et al.. Safety of Bioelectrical Impedance Analysis in Patients Equipped With Implantable Cardioverter Defibrillators. Journal of Parenteral and Enteral Nutrition, 2017, 41 (6), pp.981-985. 10.1177/0148607116633823 . hal-01282334

HAL Id: hal-01282334

https://hal-univ-rennes1.archives-ouvertes.fr/hal-01282334

Submitted on 2 Nov 2016

HAL is a multi-disciplinary open access archive for the deposit and dissemination of scientific research documents, whether they are published or not. The documents may come from teaching and research institutions in France or abroad, or from public or private research centers.
L'archive ouverte pluridisciplinaire HAL, est destinée au dépôt et à la diffusion de documents scientifiques de niveau recherche, publiés ou non, émanant des établissements d'enseignement et de recherche français ou étrangers, des laboratoires publics ou privés. 


\title{
Safety of bioelectrical impedance analysis in patients equipped with implantable cardioverter defibrillators
}

\author{
Philippe Meyer MD, ${ }^{1}$ Anne-Marie Makhlouf, ${ }^{2}$ Louis P. Mondouagne Engkolo MD, ${ }^{1}$ Florence \\ Trentaz, ${ }^{1}$ Ronan Thibault MD PhD, ${ }^{2,3}$ Claude Pichard MD PhD, ${ }^{2}$ Haran Burri MD ${ }^{1}$ \\ ${ }^{1}$ Cardiology Service, Geneva University Hospitals, Geneva, Switzerland \\ ${ }^{2}$ Nutrition unit, Geneva University Hospitals, Geneva, Switzerland \\ ${ }^{3}$ Nutrition unit, Department of Endocrinology, Diabetology and Nutrition, CHU Rennes, Rennes, \\ France
}

Key Words: Bioelectrical impedance analysis, implantable cardioverter-defibrillator, heart failure

Corresponding author: Philippe Meyer, MD, Cardiology Service, Geneva University Hospitals, Gabrielle Perret-Gentil Street 4, 1205 Geneva, Switzerland; Telephone: +41 22372 72 25; Fax:

+41 2237237 45. E-mail: philippe.meyer@hcuge.ch

Manuscript word count: 1981 (including references but excluding abstract and title page)

\section{Abstract word count: 164}

Tables: 3

Figure: 1

Conflict of Interests: There are no conflicts of interest to report.

Trial registration: NCT02349737 (http://www.clinicaltrials.gov) 


\section{ABSTRACT}

Background: Current guidelines warn from potential electromagnetic interferences (EMI) when using bioelectrical impedance analysis (BIA) to measure body composition in patients equipped with implantable cardioverter-defibrillators (ICD). We aimed to test the occurrence of EMI in a setting where this risk was experimentally maximized.

Material \& Methods: Outpatients scheduled for routine ICD controls underwent at the same time a BIA measurement using an electrical current of $0.8 \mathrm{mAmp}$ at frequencies from 5 to $100 \mathrm{KHZ}$. ICD sensitivity levels were set to maximum levels while therapies were temporarily inactivated. The device electrograms were monitored in real-time to detect sensed and/or visible EMI during BIA measurement.

Results: A total of 63 patients equipped with single- $(n=13)$, dual-chambers $(n=18)$ or biventricular $(\mathrm{n}=32)$ ICDs from 5 major manufacturers were included. No EMI were detected by the ICDs in these patients, nor were any artefacts visualized during real-time electrogram recordings.

Conclusion: BIA can be safely performed in patients equipped with ICDs without cardiac monitoring. Current guidelines should be updated accordingly. 


\section{CLINICAL RELEVANCY STATEMENT}

Measurement of body composition by bioelectrical impedance analysis (BIA) is particularly indicated in patients at risk of malnutrition such as those with chronic heart failure (HF). However there is a fear of potential electromagnetic interferences (EMI) between BIA and implantable cardioverter defibrillators (ICDs) that are often used in this population. Our findings confirm the absence of EMI between ICD and BIA. Body composition assessment by BIA using frequencies from 5 to $100 \mathrm{KHZ}$ can therefore be safely performed without cardiac monitoring in patients equipped with ICDs. 


\section{INTRODUCTION}

Bioelectrical impedance analysis (BIA) is a well validated, non-invasive and relatively inexpensive technique to measure body composition and improve nutritional status assessment. ${ }^{1}$ A comprehensive nutritional assessment is particularly indicated in patients at risk of malnutrition or weight loss, such as those suffering from chronic diseases including heart failure (HF). ${ }^{2}$ About 10 to $15 \%$ of patients with chronic HF in New York Heart Association (NYHA) classes II to IV are affected with the most severe form of body wasting named cardiac cachexia, which is a major predictor of poor clinical outcomes. ${ }^{3,4}$ Cardiac cachexia has been defined as $\geq 5 \%$ of body weight loss in $\leq 12$ months or a body mass index $(\mathrm{BMI})<20 \mathrm{~kg} / \mathrm{m}^{2}$ in association with several other criteria including low fat-free mass index (FFMI), which can be measured by BIA. ${ }^{5}$

Depending on the country, it is estimated that 25 to $46 \%$ of patients with chronic HF followed by HF specialists in Europe have an indication for an implantable cardioverter defibrillator (ICD) associated or not with cardiac resynchronisation therapy (CRT). ${ }^{6}$ Therefore BIA is expected to be performed in a significant number of HF patients equipped with ICDs. However, BIA manufacturers ${ }^{7}$ and current nutrition guidelines $^{2}$ warn from possible electromagnetic interferences (EMI) between ICDs and BIA, which is a significant barrier for its use. Indeed EMI may lead to oversensing resulting in potentially serious complications including inappropriate shocks and inhibition of pacing. To our knowledge the risk of potential EMI was tested only in a single small study that required further assessment. ${ }^{8}$ Therefore, we aimed to prospectively evaluate the potential risk of EMI between BIA and ICDs in a larger number of patients and in a setting where the risk of EMI was experimentally maximised. 


\section{METHODS}

\section{Study design and patients}

This was a single-center prospective study examining potential EMI between BIA and ICDs. During 3 months, consecutive outpatients scheduled for routine ICD controls at the device clinic of the Geneva University Hospitals were included in the study. Patients who were pacemaker-dependent or aged $<18$ years were excluded from the study. As there were no previous reports of EMI between ICDs and BIA in the literature we could not calculate a sample size for our study. We tested the hypothesis that there would be no EMI detected between BIA and ICD in a larger population equipped with a wider range of different ICD manufacturers and models compared to previous studies. During ICD interrogation by a cardiologist (LPM) all patients underwent body composition measurements using BIA by a specifically trained Ph.D. student (AMM). This protocol was approved and accepted as part of a quality control study by the Geneva University Hospitals Ethics Committee. All subjects volunteered for the study.

\section{ICD interrogation}

A standard ICD control was first performed to rule out device dysfunction, and the intracardiac electrogram (EGM) evaluated for baseline noise. Then, the sensitivity levels of the ICD were set to the maximum level while ICD therapies were temporarily inactivated in order to maximize the risk of EMI with BIA. At each frequency of the BIA current, EGMs were monitored in real-time to detect sensed and/or visible EMI (Figure 1). An EMI was defined as the detection of unexpected signals due to the action of the electrical field. Presence of new artefacts visible on the real-time EGM during BIA, but 
undetected by the device, were also noted. To verify the absence of EMI, EGMs and device marker channels were saved and printed for analysis during the entire BIA measurement. At the end of the experiment, the sensitivity levels were reprogrammed to their initial settings and the ICD therapies were reactivated.

\section{BIA measurement}

After skin cleaning with $70 \%$ ethanol 4 adhesive electrodes (3M Red Dot T, 3M Health Care, Borken, Germany) were placed on the dorsal side of the left hand, left wrist, left foot, and left ankle while the patient was lying supine with hand palms facing inwards. An electrical current of $0.8 \mathrm{mAmp}$ was produced successively at 3 different frequencies $(5,50,100 \mathrm{KHz})$ by a generator/analyser (Nutriguard M, DataInput, Gmbh, Darmstadt, Germany) during approximately 2 minutes to measure whole-body resistance and reactance. $^{1}$

\section{Data collection and statistical analysis}

On the day of the ICD control, each patient was questioned about symptoms for determination of NYHA class and weight changes during the previous year. Weight, height and vital signs were measured. Body Mass Index (BMI) was calculated as weight

(kg) divided by squared height $\left(\mathrm{m}^{2}\right)$. Information on ICD type, implant date and indication as well as etiology of heart disease and left ventricular ejection fraction (LVEF) were retrieved from the Geneva University Hospitals electronic medical record.

Descriptive statistics were assessed and results expressed as mean \pm standard deviation (SD) for continuous variables and number of patients (\%) for categorical variables. 


\section{RESULTS}

We included 63 patients (54 men) with a mean age of $64.8 \pm 14.6$ years, mean LVEF of $32.1 \pm 16.5 \%$ and mean BMI of $27.9 \pm 4.8 \mathrm{~kg} / \mathrm{m}^{2}$. Primary prevention was the main ICD indication (62\%), a CRT being implanted in more than half of the patients. Other patients' characteristics are detailed in Table 1. The different ICD manufacturers and models are listed in Table 2. Five major companies were represented: Medtronic $(\mathrm{n}=20)$, Boston scientific $(n=15)$, St-Jude $(n=13)$, Biotronik $(n=11)$, Sorin Group $(n=4)$. Table 3 details the maximum programmable sensitivity for right atrial, right ventricular and left ventricular electrodes according to each manufacturer.

No EMI were detected by the ICDs during BIA measurements assessed at three current frequencies in the 63 participants. Further, no artefacts were visualized during the EGM recordings in any of the ICDs. (Figure 1, Table 2).

\section{DISCUSSION}

In this prospective study including a wide range of different ICD manufacturers and models we did not detect any interference between BIA and ICDs even if this risk was experimentally maximized. Our study thus demonstrates that BIA using an electrical current of $0.8 \mathrm{mAmp}$ at frequencies from 5 to $100 \mathrm{KHZ}$ can safely be performed without cardiac monitoring in patients equipped with ICDs. This finding is particularly important for the management of patients with severe chronic HF implanted with ICDs who may present undernutrition or cardiac cachexia and benefit from targeted nutritional interventions. 
Electromagnetic fields generated by an electrical current passing through an electrically operated device may produce EMI with ICDs. However the high frequencies used to assess body composition by BIA $(5,50,100 \mathrm{kHz})$ are attenuated by band-pass filters that are centered around the physiological frequencies of endocavitary signals (20$60 \mathrm{~Hz}$ ). In addition, pacemakers and ICD filters are equipped with ceramic feedthrough filters that further attenuate EMI in the $30 \mathrm{MHz}-10 \mathrm{Ghz}$ range). These filters provide protection from high-frequency signals generated by devices such as cell phones, microwave ovens and radars $(450 \mathrm{MHz}$ to $12 \mathrm{GHz}) .{ }^{9,10}$

Buch et al. investigated the impact of BIA measurement on ICDs in 20 patients with HF using one type of BIA monitor at three different frequencies $(5,50$ and 500 $\mathrm{KHz}$ ) and found no EMI. ${ }^{8}$ Our study differs from this previous report in two main respects. First, our sample size is more than 3 times larger including 29 ICD types from 5 different manufacturers. Second, to maximize the risk of EMI with BIA, we programmed the sensitivity levels of the ICD to the maximum level and placed the BIA electrodes on the left side of the body (as close as possible to the pulse generator). For these reasons we believe that our study now provides confirmation that there is negligible risk of using BIA in patients equipped with ICDs.

BIA is a well validated and easy-to-use method to measure body composition as part of a comprehensive nutritional assessment. BIA allows the determination of fat-free mass (FFM), body fat (BF), body cell mass (BCM), and total body water (TBW). FFMI calculated as the ratio of FFM to squared height is now part of the novel definition of cachexia. ${ }^{5}$ Cardiac cachexia is associated with a $2-3$ fold increase in mortality compared to non-cachectic patients, which corresponds to a 20 to $40 \%$ one-year mortality. ${ }^{3,4}$ 
Further studies are urgently needed to better understand the pathophysiology of cardiac cachexia and to develop novel treatments. ${ }^{4,11,12}$ A comprehensive nutritional assessment using BIA in the most severe HF patients often implanted with ICDs will be important in future trials, some of which being already under way (ClinicalTrials.gov identifier: NCT01864733).

Several limitations need to be considered. First, even if the largest to date, our study only tested 63 patients and our results cannot be generalized to all ICDs available on the market. However we included different models of the five main ICD manufacturers and maximized the risk of EMI in our protocol. Therefore we believe that the risk of EMI can be considered as negligible for all ICDs and pacemakers (which are equipped with similar filters as ICDs, and have lower sensitivity settings). Second, we used a generator producing current frequencies of 5,50 and $100 \mathrm{KHz}$ and cannot exclude potential EMI with BIA devices that may use other frequency regimens such as pulsing at lower frequencies that may be detected by devices.

\section{CONCLUSION}

To conclude, our study confirms the absence of EMI between BIA and ICD. Body composition assessment by BIA using frequencies from 5 to $100 \mathrm{KHZ}$ can therefore be safely performed without cardiac monitoring in patients equipped with ICDs. Current nutrition guidelines should be updated accordingly. 


\section{Acknowledgements}

The authors gratefully thank Mrs Nicole Schaerer, Béatrice Sanchez and Carine Stettler for their help to recruit patients and all the technicians of the Cardiology Service who participated in the ICD controls.

\section{Conflict of Interest disclosures}

The authors report no conflicts of interest.

\section{Funding support}

This study did not receive any external funding. 


\section{References}

1. Kyle UG, Bosaeus I, De Lorenzo AD, et al. Bioelectrical impedance analysis-part i: Review of principles and methods. Clin Nutr. 2004;23:1226-1243.

2. Kyle UG, Bosaeus I, De Lorenzo AD, et al. Bioelectrical impedance analysis-part ii: Utilization in clinical practice. Clin Nutr. 2004;23:1430-1453.

3. Anker SD, Laviano A, Filippatos G, et al. Espen guidelines on parenteral nutrition: On cardiology and pneumology. Clin Nutr. 2009;28:455-460.

4. von Haehling S, Anker SD. Prevalence, incidence and clinical impact of cachexia: Facts and numbers-update 2014. J Cachexia Sarcopenia Muscle. 2014;5:261-263.

5. Evans WJ, Morley JE, Argiles J, et al. Cachexia: A new definition. Clin Nutr. 2008;27:793-799.

6. John Camm A, Nisam S. European utilization of the implantable defibrillator: Has 10 years changed the 'enigma'? Europace. 2010;12:1063-1069.

7. Http://www.Data-input.De/media/pdf english 2014/instructions-for-use-nutriguardms.Pdf.

8. Buch E, Bradfield J, Larson T, Horwich T. Effect of bioimpedance body composition analysis on function of implanted cardiac devices. Pacing Clin Electrophysiol. 2012;35:681-684.

9. Beinart R, Nazarian S. Effects of external electrical and magnetic fields on pacemakers and defibrillators: From engineering principles to clinical practice. Circulation. 2013;128:2799-2809.

10. Hayes DL, Wang PJ, Reynolds DW, et al. Interference with cardiac pacemakers by cellular telephones. $N$ Engl J Med. 1997;336:1473-1479.

11. von Haehling S, Anker SD. Treatment of cachexia: An overview of recent developments. Int J Cardiol. 2015;184:736-742.

12. von Haehling S, Lainscak M, Springer J, Anker SD. Cardiac cachexia: A systematic overview. Pharmacol Ther. 2009;121:227-252. 
Figure legends

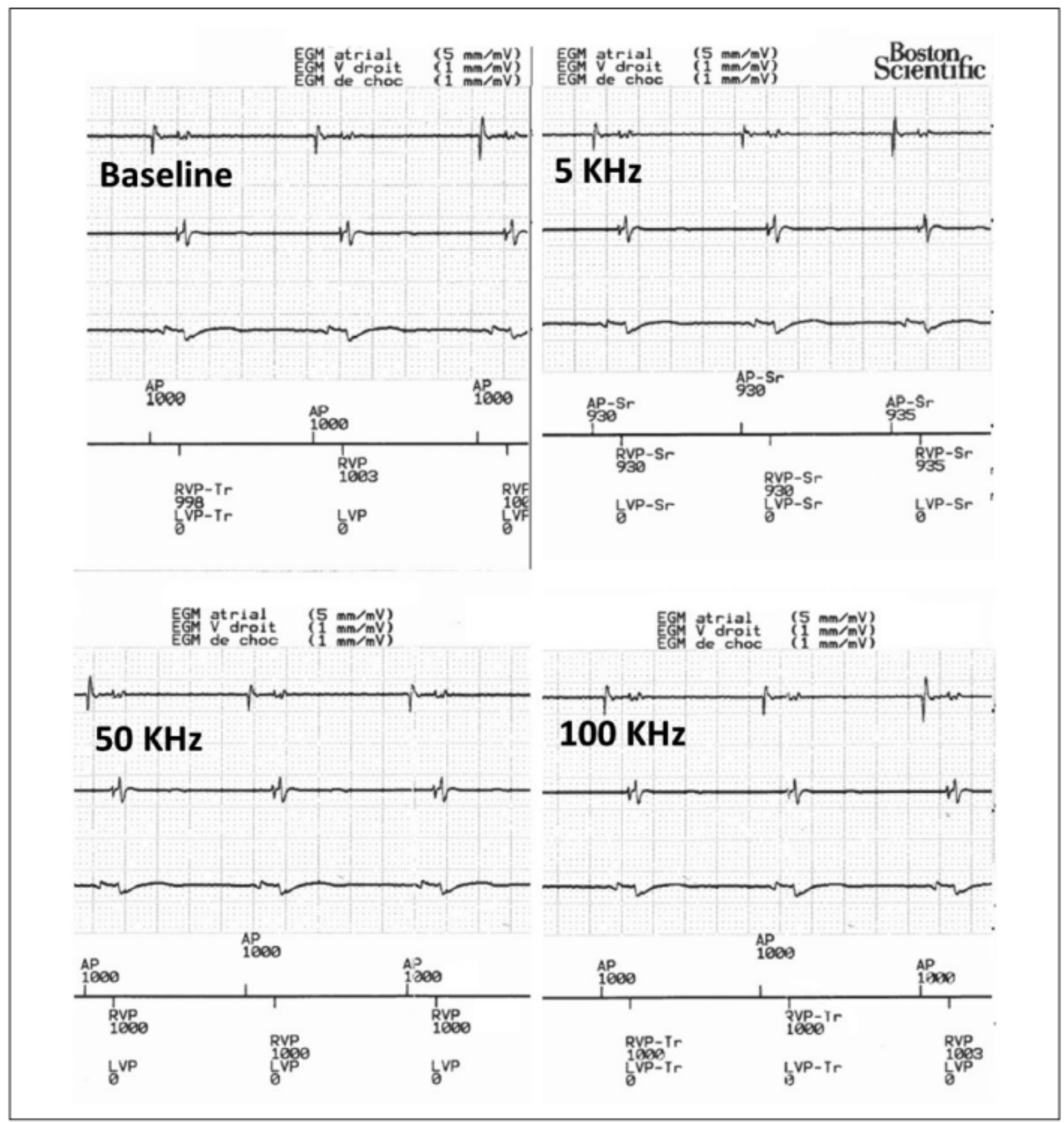

Figure 1. Examples of real-time electrogram printouts of a biventricular defibrillator at baseline and during exposure to BIA at various frequencies. Note the absence of visible 
or sensed artefacts on any of the channels (atrial on the top, right ventricle in the middle and the far-field can to right ventricular coil on the bottom tracings).

\section{Tables}

Table 1. Patient Characteristics. ${ }^{a}$

\begin{tabular}{lc}
\hline Patient Characteristics $(\mathrm{N}=63)$ & Mean $\pm \mathrm{SD}$ \\
\hline Age, $\mathrm{y}$ & $64.8 \pm 14.6$ \\
Men, $\mathrm{n}(\%)$ & $54(85.7)$ \\
Body mass index, $\mathrm{kg} / \mathrm{m}^{2}$ & $27.9 \pm 4.8$ \\
Heart rate, bpm & $76.8 \pm 12.1$ \\
Systolic blood pressure, $\mathrm{mm} \mathrm{Hg}$ & $130.3 \pm 18.2$ \\
Diastolic blood pressure, $\mathrm{mm} \mathrm{Hg}$ & $70.9 \pm 11.3$ \\
LVEF, \% & $32.2 \pm 16.5$ \\
Heart disease etiology, $\mathrm{n}(\%)$ & \\
Ischemic & $28(44.4)$ \\
Nonischemic & $35(55.6)$ \\
NYHA class, $\mathrm{n}(\%)$ & \\
I & $14(22.2)$ \\
II & $33(52.4)$ \\
III & $15(23.8)$ \\
IV & $1(1.6)$ \\
ICD type, n (\%) & \\
Single-chamber & $13(20.6)$ \\
Dual-chamber & $18(28.6)$ \\
CRT-D & $32(50.8)$ \\
Device indication & \\
Primary prevention & $39(61.9)$ \\
Secondary prevention & $24(38.1)$ \\
Time since implantation, mo & $23.8 \pm 20.9$ \\
\hline
\end{tabular}

bpm, beats per minute; CRT-D, cardiac resynchronization therapy; ICD, implantable cardioverter-defibrillator; LVEF, left ventricular ejection fraction; NYHA, New York Heart Association.

${ }^{a}$ Data are expressed as mean \pm standard deviation (SD) unless stated otherwise. 
Table 2. ICD Manufacturers and Types.

\begin{tabular}{|c|c|c|}
\hline Manufacturer (n) & ICD Type (n) & $\begin{array}{c}\text { Visualized } \\
\text { Interference } \\
\text { at } 5,50 \text {, and } \\
100 \mathrm{kHz}\end{array}$ \\
\hline \multicolumn{3}{|l|}{ Medtronic (20) } \\
\hline Evera XT & VR (2); DR (2) & No \\
\hline Protecta & DR (1); CRT-D (5) & No \\
\hline Secura & VR (1); DR (1) & No \\
\hline Viva quad XT & CRT-D (4) & No \\
\hline Viva XT & CRT-D (5) & No \\
\hline \multicolumn{3}{|c|}{ Boston Scientific (15) } \\
\hline Autogen X4 & CRT-D (3) & No \\
\hline Cognis & CRT-D (2) & No \\
\hline Incepta & DR (2); CRT-D (2) & No \\
\hline Teligen & VR (3); DR (2) & No \\
\hline Vitality 2 & VR (1) & No \\
\hline \multicolumn{3}{|l|}{ St-Jude (13) } \\
\hline Ellipse & VR (1); DR (2) & No \\
\hline Fortify ST DR & DR (2) & No \\
\hline Quadra Assura & CRT-D (4) & No \\
\hline Unify & CRT-D (4) & No \\
\hline \multicolumn{3}{|l|}{ Biotronik (11) } \\
\hline Ilesto 7 & VR (1); DR (2); CRT-D (2) & No \\
\hline Iperia & VR (2) & No \\
\hline Lumax & VR (1); DR (2); CRT-D (1) & No \\
\hline \multicolumn{3}{|l|}{ Sorin (4) } \\
\hline Paradym RF & VR (1); DR (3) & No \\
\hline
\end{tabular}

CRT-D, biventricular defibrillator; DR, dual chamber, ICD, implantable cardioverter-defibrillator; VR, single chamber.

Table 3. Maximum Programmable Sensitivity According to Device Manufacturer. ${ }^{\text {a }}$

\begin{tabular}{lccc}
\hline Manufacturer & Atrial, mV & $\begin{array}{c}\text { Right } \\
\text { Ventricle, mV }\end{array}$ & $\begin{array}{c}\text { Left } \\
\text { Ventricle, mV }\end{array}$ \\
\hline Biotronik & 0.2 & $0.4 / 0.5$ & 0.5 \\
Boston Scientific & 0.15 & 0.15 & 0.15 \\
Medtronic & 0.15 & 0.15 & $\mathrm{~N} / \mathrm{A}$ \\
St-Jude Medical & 0.15 & 0.15 & $\mathrm{~N} / \mathrm{A}$ \\
Sorin & 0.2 & 0.4 & N/A \\
\hline
\end{tabular}

N/A, not available.

aDifferent models of the same manufacturer may have different sensitivity settings. 